\section{Visão Estratégica na Atividade \\ Turística sob a Perspectiva das \\ Entidades e Organizações do Setor: um estudo em Natal - RN}

\author{
Strategic Vision in Tourist Activity from the Perspective of \\ Industry Entities and Organizations: a study in Natal - RN
}

\section{Benny Kramer Costa ${ }^{1}$} Carla Maria Rodrigues Muniz ${ }^{2}$ Adalberto Américo Fischmann ${ }^{3}$ João Paulo Lara de Siqueira ${ }^{4}$

\section{PALAVRAS-CHAVE: estratégia; futuro; turismo; visão e organizaçōes.}

ABSTRACT: This article discusses how entities of to the tourist area in Natal (RN) consider future's impact and its relation to their strategies. The theoretical aspects of the future's foresight are introduced and the results of a case study, with a field research undertaken with the managers of government institutions, private organizations and universities, all of them from Natal $(\mathrm{RN})$. The study unveiled that the managers of these institutions are concerned with strategic issues and are aware of the necessity of an efficient planning for the construction of their desired future, but only try to keep their status quo and past achievements, without a truly effective preoccupation with the future. The conclusion is that in those organizations there is no shared vision of the future, due to factors like the lack of a common understanding to their own activity and to the different perceptions of what is being done to face de future's challenges.

KEYWORDS: strategy, future, tourism, vision and organizations.

\section{Introdução}

RESUMO: Este artigo discute como as entidades ligadas à área de turismo em Natal (RN) consideram o impacto do futuro e sua relação com as estratégias adotadas. São apresentados os aspectos teóricos da visão de futuro e os resultados de um estudo de caso, com pesquisa de campo, realizado com os dirigentes de instituiçōes privadas, governamentais e de ensino de Natal (RN). O estudo revelou que os gestores dessas entidades preocupam-se com questōes estratégicas e reconhecem a necessidade de um planejamento eficaz para a construção do futuro desejado, mas procuram manter o status quo e suas conquistas, sem preocupaçāo efetiva com o porvir. Concluiu-se que, nessas entidades, não há a visão de futuro compartilhada por causa de fatores como a falta de sintonia quanto à própria atividade e as percepçōes diferentes sobre o que está sendo feito atualmente para enfrentar os desafios do futuro.

1. Doutor em Administração pela FEA/USP; professor do Curso de Turismo da ECA/USP. Contato: Rua João de Canha, 160 - 03178-160 - São Paulo-sp; e-mail: bennycosta@yahoo.com.br.

2. Mestre em Administração pela UFRN; professora e coordenadora da pós-graduação da Faculdade de Natal - FAL. Contato: Rua Ciro Monteiro, 1184/600 - 59020-340 - Natal-RN; e-mail: carla.muniz@ falnatal.com.br.

3. Doutor em Administração pela FEA-USP; professor titular de Administração da FEA-USP. Contato: Rua Costa Carvalho, 61/141 - 05429-130 - São Paulo-sp; e-mail: aafischm@usp.br.

4. Doutor em Administração pela FEa/USP; professor da UniversidadeCidade de São Paulo. Contato: Rua Caraíbas, 1018/61 -05020-000 - São Paulo-sp; e-mail: jpsiq@usp.br.
Nos últimos anos, o mundo tem passado por transformações significativas, como a abertura da China para o capitalismo, a disseminação do uso da Internet, a globalização econômica, as mudanças nas relações entre países e os atentados de 11 de setembro. Essas e outras transformações, difíceis de ser imaginadas apenas há alguns anos, têm levado as organizações e instituições a se questionar sobre o que o futuro lhes reserva e sobre a possibilidade de alcançarem ou não seus objetivos e intentos estratégicos.

É nesse contexto que se concebe o presente estudo, que tem como objetivo analisar o conceito de visão e sua utilização na atividade estratégica do turismo, a partir dos níveis dirigentes de diversas instituições representativas desse segmento, com uma pesquisa realizada na cidade de Natal (RN), um dos principais pólos de atração turística da Brasil. Tal escolha tem a ver com a atenção que tem merecido essa atividade, em termos locais e regionais, pela fase crescente em que se encontra, o resultado alcançado, além do fato de ser encarada como extremamente promissora em termos econômicos e sociais. Parte-se da preocupação básica de buscar conhecer como essas organizações lidam com a questão do futuro do setor e de suas próprias empresas, não se deixando de analisar, também, as limitações, os obstáculos, os impactos e as influências de médio e longo prazos na atividade turística, que é fundamental para toda a região. 
Dessa forma, o trabalho em pauta procura verificar como a relação entre o futuro do setor e a forma como cada organização se posiciona diante dele, avaliando-se a percepção da situação atual; a visão estratégica (do setor e da organização); a existência de uma visão compartilhada (entre os responsáveis pelas decisões estratégicas) e a interdependência entre os stakeholders. Destaca-se a visão de futuro compartilhada, considerando o alinhamento com a estratégia da organização, o envolvimento e comprometimento dos seus membros com os objetivos, desempenho e resultados, e com a capacidade de aprendizagem, visando à construção de um futuro promissor e consistente.

O presente artigo consiste basicamente numa breve introdução, uma abordagem teórica com o levantamento de conceitos e construções de autores relevantes e suas obras sobre a visão estratégica, a análise dos resultados da pesquisa de campo realizada com as principais instituições que compõem o turismo de Natal, e a conclusão a que se chega com o estudo.

\section{0 conceito de visão estratégica}

Diversos autores, ao longo das últimas duas décadas, têm estudado o tema "visão" sob vários aspectos. O Quadro 1 apresenta esses autores e uma taxonomia de seus trabalhos.

É importante conceituar visão por duas razões: uma, teórica; outra, de ordem operacional. Do ponto de vista teórico, trata-se de um termo que tem ligação tanto com a estratégia como com o futuro. No aspecto operacional, faz-se necessário conceituá-la por ser objeto de investigação da pesquisa de campo deste trabalho.

Segundo Johnson e Scholes (1999: 13), visão, o mesmo que intenção estratégica, é um estado desejado para a organização no futuro. Já para Hart (1999: 411), visão é a manifestação das aspirações de uma empresa em relação ao futuro; para ser bem-sucedida, ela precisa alicerçar--se no futuro, prover orientação e congruência para o trabalho subseqüente, e ter alguma constância ao longo do tempo.

Para Hax e Majluf (1996: 185), a visão deve prover um senso de propósito para a organização, possuir um significado de desafio atingível e apontar a direção básica a ser perseguida. Hamel e Prahalad (1995: 84), por sua ótica, evidenciaram não acreditar que uma empresa possa ter sucesso sem uma visão articulada do amanhã. Todavia, esses autores ressaltaram que aquilo que está realmente em jogo é a capacidade da empresa de executar sua visão.

No estudo em questão, foi utilizada uma definição operacional de visão que compreende dois componentes básicos: uma configuração futura dese- jada para a organização e um ambiente futuro onde essa configuração possa ser bem-sucedida.

\section{Relação entre visão e o ambiente futuro}

Embora as definições de visão sejam unânimes em fazer referência a uma situação futura, nem todas deixam explícito que o ambiente futuro deve ser considerado, e poucas explicam como ele poderia ser considerado. Isto posto, uma investigação de como o ambiente futuro deve ser considerado na visão da empresa é justificável.

Segundo Godet (2001: 255), a visão de uma corporação normalmente inclui quatro dimensões: uma ambição para o futuro, um desejo coletivo, um conjunto de valores que é compartilhado, e os eixos das estratégias de médio e longo prazos. Entretanto, esse autor fez um alerta a respeito da visão da corporação, advertindo que as incertezas a respeito do ambiente precisam ser consideradas.

Para Schoemaker (2002: 96), a visão estratégica deve dizer em qual direção a empresa irá competir, como irá competir e quais as competências necessárias para isso. Entretanto, uma visão só será robusta se explicar como a empresa se comportará nos diversos ambientes futuros possíveis, descritos por meio de técnicas de criação de cenários.

Quadro 1. Principais autores e trabalhos sobre a visão estratégica

\begin{tabular}{|l|l|c|}
\hline Classificação & Autor & Ano \\
\hline \multirow{4}{*}{ Abordagens iniciais } & El-Namaki & 1992 \\
\cline { 2 - 3 } & Nakahara \& Isono & 1992 \\
\cline { 2 - 3 } & Wilson & 1992 \\
\cline { 2 - 3 } & Coulson-Thomas & 1992 \\
\cline { 2 - 3 } & Bertodo & 1991 \\
\cline { 2 - 3 } & Bertodo & 1990 \\
\cline { 2 - 3 } & Shirley & 1989 \\
\hline Ênfase na visão compartilhada & Brabet \& Klemm & 1994 \\
\hline
\end{tabular}


Quadro 1. Principais autores e trabalhos sobre a visão estratégica (cont.)

\begin{tabular}{|c|c|c|}
\hline Classificação & Autor & Ano \\
\hline Ênfase na visão periférica & Haeckel & 2004 \\
\hline \multirow{6}{*}{$\begin{array}{l}\text { Aplicação em atividades setoriais } \\
\text { específicas }\end{array}$} & Aidemark \& Lindkvist & 2004 \\
\hline & Wittlöv & 2001 \\
\hline & Hassan \& McCaffer & 2002 \\
\hline & Fraser \& Olsen & 2002 \\
\hline & Moule & 1999 \\
\hline & Cavanagh \& Sonstelie & 1998 \\
\hline Empresas familiares & Athanassiou et al & 2002 \\
\hline Aplicação para setores econômicos & Currie & 2004 \\
\hline \multirow{3}{*}{ Elo com a inovação } & Ahmed \& Abdalla & 1999 \\
\hline & Currie & 1999 \\
\hline & Johne & 1999 \\
\hline \multirow{7}{*}{ Ênfase geral } & Lissack \& Roos & 2001 \\
\hline & Xu, Kaye \& Duan & 2003 \\
\hline & Ache & 2000 \\
\hline & Thornberry & 1997 \\
\hline & Gratton & 1996 \\
\hline & Peppard & 1996 \\
\hline & Markley & 1994 \\
\hline Área de turismo especificamente & Ritchie & 1999 \\
\hline
\end{tabular}

A relação entre visão e ambiente futuro foi percebida por Ashley e Hall (1985: 63), que entenderam que a primeira etapa da formulação da visão estratégica deve quebrar a idéia de um futuro que seja fruto da extrapolação do presente.
Esses autores elaboraram um quadro sinóptico dessa idéia, no qual são usados cenários como ponto de partida para a construção da visão estratégica. Esse quadro pode ser observado na Figura 1, a seguir.

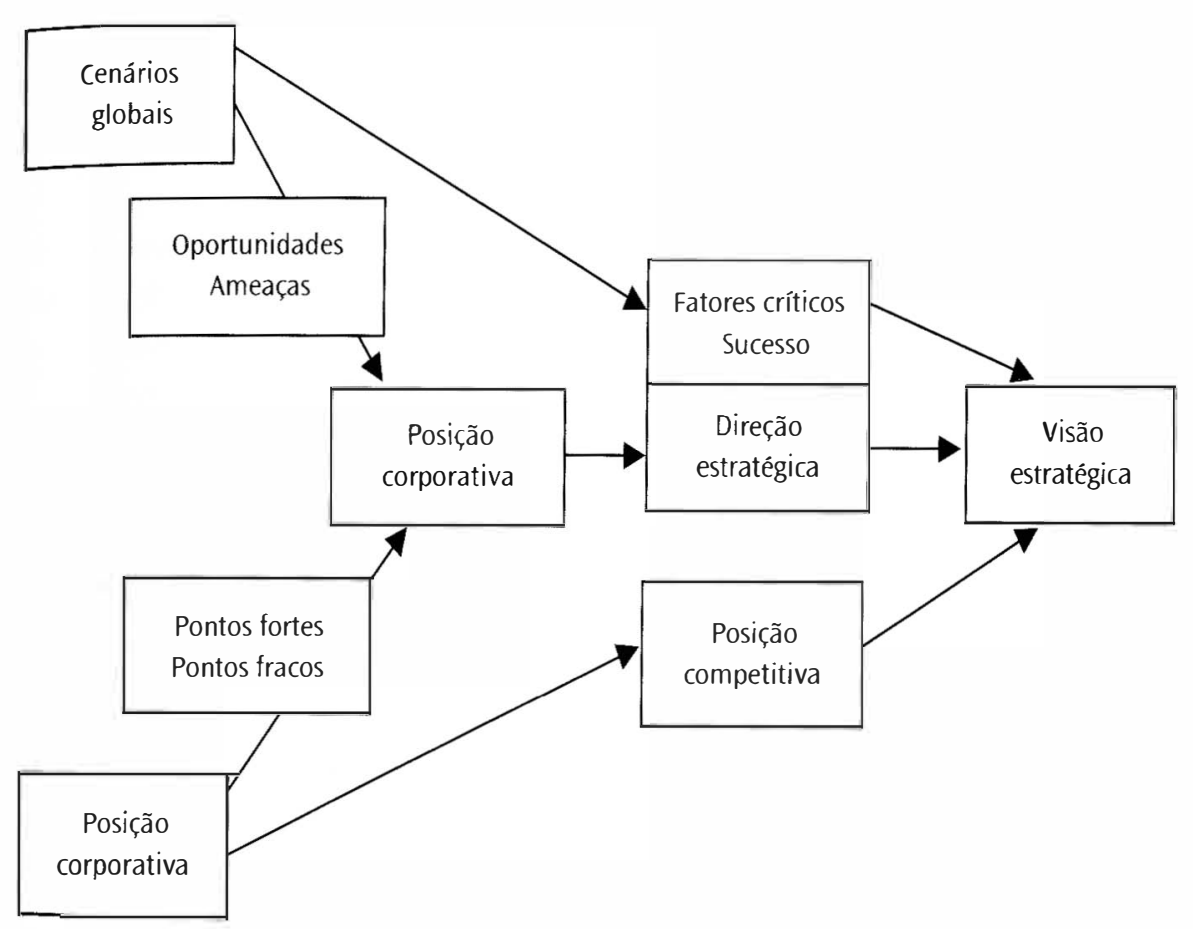

Figura 1. A função da visão estratégica

Fonte: Ashley e Hall (1985: 63).

\section{A visão compartilhada e sua importância}

Outro aspecto importante a ser ressaltado é a questão da visão compartilhada. Vários autores atestaram a importância de que a visão nas organizações seja compartilhada e que, portanto, haja um comprometimento dos membros dessa organização para com ela.

Para Senge (1998: 234), a visão compartilhada é essencial para a organização que aprende, pois fornece o foco e a energia para a aprendizagem. Além disso, Senge (1998: 239) acrescentou que, apesar de a visão compartilhada surgir a partir de visões pessoais, as organizações devem ter o cuidado de não infringir as 
liberdades individuais. Costa (2002: 36) concordou com Senge, afirmando que uma visão compartilhada tem valor inestimável para a organização, pois sua função é explicitar o que a empresa quer ser; unificar as expectativas; dar um sentido de direção; e ajudar o envolvimento e comprometimento das pessoas.

\section{Visão de futuro como competência essencial e vantagem competitiva}

Uma interessante relação entre visão e competência essencial foi desenvolvida por Major et al. (2001: 94), que abordaram a ligação entre o conceito de competência essencial e foresight. Mais especificamente, esses autores explicaram que o conceito de competência essencial requer o conhecimento da visão de futuro.

Para demonstrar tal proposição, Major et al. (2001: 96) recorreram ao conceito de competência essencial desenvolvido por outros autores. Primeiramente, citaram o conceito de competência distintiva proposto, inicialmente, por Hofer e Schendel, no qual a competência distintiva se define como uma capacidade de determinar em quais indústrias a empresa deve entrar.

Major et al. (2001: 101) apoiaram-se também em Hamel e Prahalad (1995), que em The Core Competence of the Corporation afirmaram que as habilidades, atitudes e atributos dos gerentes de uma empresa são fundamentais para a competência essencial da visão da estratégia, e que o perfil dos gerentes faz parte da aprendizagem coletiva na organização. Major et al., então, explicaram que os elementos críticos para a visão de futuro são os mesmos que para a competência essencial.

Major et al. (2001: 100) analisaram e classificaram os níveis de competência das empresas em foresight, em função da atitude dos gerentes quanto ao futuro, e elaboraram um quadro explicativo (ver Figura 2).

Uma outra importante relação entre visão de futuro e vantagem competitiva também foi estabelecida por De Geus (1988: 71), que se pronunciou a respeito do assunto ao analisar o aprendizado de cenários nas organizações, quando viu na habilidade de aprender mais rapidamente que os concorrentes talvez a única vantagem competitiva sustentável.

\section{Método empregado no estudo}

O estudo realizado teve natureza exploratória, a qual, de acordo com Selltiz et al. (1965: 60-1), objetiva a formulação de um problema para investigação ou

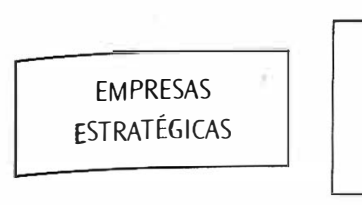

- Alto grau de conhecimento e aplicação de foresight.

- Pouca dependência do canal de distribuição.

- Relacionamento externo muito importante.
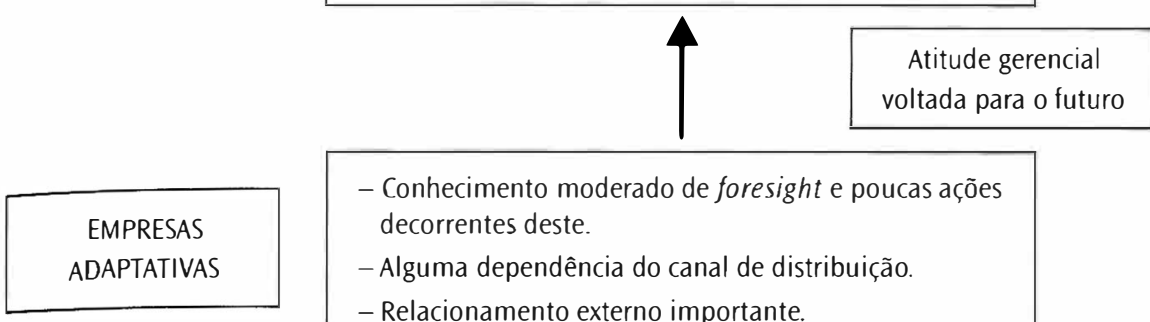

- Conhecimento moderado de foresight e poucas ações decorrentes deste.

- Alguma dependência do canal de distribuição.

- Relacionamento externo importante.

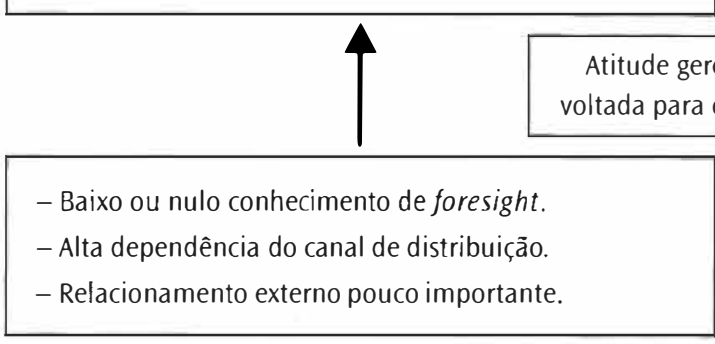

Figura 2. Competência estratégica

Fonte: Major et al. (2001: 100)

criação de hipóteses, bem como apresenta as funções de aumentar o conhecimento sobre uma situação em que se pretende realçar tal estudo, esclarecer conceitos, estabelecer prioridades para futuras pesquisas e apresentar um recenseamento de problemas no campo das Ciências Sociais.

Como o trabalho de pesquisa realizado se propôs a conhecer melhor e a delinear a visão estratégica, por parte dos dirigentes, ligada à atividade do turismo em Natal (RN), não há dúvida quanto ao seu caráter exploratório.

A abordagem empregada para que as conclusões desejadas pudessem ser atingidas foi a fenomenológica, com o uso do método de estudo de caso no formato de estudo de casos múltiplos. Para Yin (1994: 34-7), as vantagens de utilizar esse método, nesse formato, correspondem aos seguintes aspectos:

1. o pesquisador necessita somente examinar as respostas de uma mesma questão ou das questões existentes, dentro de cada caso, para iniciar a elaboração de comparações cruzadas dos casos (cross-case), o que facilita o desenvolvimento da análise dos resultados para interesses específicos; 
2. não são vistos separadamente os capítulos e sessões destinadas a cada tipo individual, mas sintetizadas as informações de todos os respondentes, as quais, por sua vez, são organizadas em torno de cada tópico ou módulo do modelo de pesquisa.

A população de interesse do estudo foi composta por todas as organizações e instituições que atuam na atividade do turismo no município de Natal (RN), integrada por empresas, organismos governamentais, associações de classe e universidades que estudam o turismo. A relação dos tipos de organizações foi obtida por intermédio de dados secundários, mais especificamente das fontes a seguir: Cadastro do Sindicato de Hotéis, Restaurantes, Bares e Similares de São Paulo, e Turismo Paulista/1997 - Anuário de Hospedagem, Turismo e Serviços do Estado de São Paulo.

A amostra de organizações pesquisadas foi escolhida de forma intencional e por conveniência, tendo sido selecionados representantes das organizações e instituições mais representativas que compõem o setor de turismo na cidade de Natal (RN). Essa seleção obedeceu aos seguintes pontos:

- no âmbito público: Secretaria Estadual de Turismo do Rio Grande do Norte (Estado), Secretaria Municipal de Turismo de Natal (município) e Universidade Federal do Rio Grande do Norte - UFRn (instituição de ensino superior);

- no âmbito privado: Associação dos Meios de Hospedagem e Turismo AMHT (associação de classe patronal); Pirâmide Palace Hotel (empresa de hotelaria) e Banco do Nordeste/Pólo Costa das Dunas (banco de fomento com linhas de financiamento voltadas para o turismo, que coordena o pólo turístico Costa das Dunas, em Natal (RN).

Assim, foram pesquisados seis casos, agrupados em seis elementos. A escolha da amostra deu-se em função da importância dessas organizações para o turismo local e da contribuição que os profissionais envolvidos com as questões estratégicas dessas organizações selecionadas poderiam dar para o estudo.

\section{Análise dos resultados}

A partir do estudo de campo realizado com executivos e diretores de estabelecimentos do setor do turismo pôde-se perceber que os responsáveis pelas decisões de natureza estratégica demonstraram estar abertos a discutir novas idéias, além de dispostos a melhorar os seus processos atuais. Tanto é que se colocaram à disposição para responder à pesquisa com facilidade, solicitando, quando necessário, mais informações sobre o que estava sendo perguntado.

A despeito do interesse demonstrado, mostraram-se céticos sobre como os conhecimentos teóricos e conceituais poderiam ajudá-los em seus negócios, e também no quanto cada um teria o poder de interferir no curso dos acontecimentos presentes, visando à construção de um futuro desejável tanto para sua atividade como para o desenvolvimento do segmento como um todo. A preocupação dominante consistiu em manter o que já fora conquistado, deixandose para pensar nas oportunidades e/ou ameaças à medida que elas se apresentem.

Os respondentes aparentaram ter dificuldades em visualizar o que acontecerá no futuro do segmento e de suas organizações, talvez porque a análise do ambiente tenha sido feita de maneira restrita aos acontecimentos passados e atuais. Os representantes das organizações pesquisadas reconheceram que o futuro encerra um grande número de possibilidades ("tudo pode acontecer"), que seria oportuno tomar providências agora e, também, que o desenvolvimento do turismo dependerá de um planejamento eficaz na construção desse futuro. Apesar disso, não pareciam preocupados com a concorrência, nem com os dias que estão por vir. Mostraram acreditar que o turismo continuará a crescer e que só precisarão se organizar para que os problemas sejam minimizados.

No que tange à visão de futuro, procurou-se identificar qual a percepção dos entrevistados sobre a situação atual do turismo, se existe uma visão compartilhada sobre o que é necessário ser feito para o desenvolvimento do setor; de que modo é visualizado o futuro, tanto de suas organizações como do próprio segmento num horizonte de dez anos; se alguma estratégia está sendo implementada hoje, visando à construção desse futuro, e por fim, como é vista a interdependência existente entre as organizações e instituições do setor.

Em geral, observou-se certa unanimidade em reconhecer que o turismo está em ótima fase, apresentando um crescimento expressivo. Os entrevistados demonstraram acreditar que esse crescimento tende a aumentar ao longo dos anos e, por isso, preocupam-se com a organização e o direcionamento desse processo. Consideraram, ainda, que tal crescimento não é conseqüência de uma ação específica do governo, e que, em conseqüência disso, tem sido desordenado e poderia até ter sido maior se houvesse um planejamento eficaz. Apesar desse ponto de vista, eles afirmaram que a construção da Via Costeira, a ação da iniciativa privada (dos hoteleiros), os investimentos feitos em infra-estrutura, propiciados pelo prodetur i e il, e a criação dos fóruns de turismo (Pólo Costa das Dunas e CONETUR) contribuíram muito para a realidade atual. 
Parte do otimismo observado deveu-se ao fato de que o presidente da EMBRATUR, quando esteve em Natal, em abril de 2004, mencionou que os destinos emergentes hoje, em nível mundial, são: África do Sul, Austrália e o Nordeste brasileiro. Todos eles revelaram acreditar que o Rio Grande do Norte tem todas as condições para se destacar dos outros Estados e assumir a liderança na região. Mas para isso ocorrer é necessário a profissionalização tanto dos empresários como do governo nas suas diversas esferas.

O Quadro 2 condensa a percepção da situação atual do setor, os pontos positivos e negativos, e ainda o que consideraram sobre o que deveria ser feito para o segmento se desenvolver.

O entendimento dos entrevistados sobre a visão compartilhada é de que ela começou a ser desenvolvida a partir da criação de diversos fóruns para discussão das necessidades do setor, como o Pólo Costa das Dunas e o CONETUR. A partir desse exercício, as organizações do setor tiveram a oportunidade de perceber as implicações que cada decisão possui e de expandir sua visão sobre o negócio do turismo. Ressaltou-se que, mesmo que esses eventos proporcionem um espaço para a discussão do futuro do turismo, as soluções se restringem ao que já está pré-definido no Plano de Desenvolvimento Integrado do Turismo Sustentável (PDrrs).

Percebeu-se que aquilo que está sendo discutido e acompanhado nesses fóruns já foi planejado, e que a partir daí só há a possibilidade de acompanhamento da realização das ações já definidas. Embora tais encontros favoreçam o desenvolvimento da visão compartilhada, não são usados para chegar a um consenso sobre o futuro desejado para o turismo e os papéis de cada um para sua construção, nem para a definição de estratégias setoriais. Houve concordância quanto ao fato de que deveria haver uma participação maior tanto da sociedade como das empresas, o que, por sua vez, mostra que não existe ainda uma conscientização sobre a necessidade de uma definição do que se deseja para o turismo e do que precisa ser feito.

Os respondentes da pesquisa revelaram acreditar que o turismo ainda não é visto como uma atividade que traz benefícios para todos, e que esse fato dificulta a ação conjunta dos envolvidos. Também se verificou que os entrevistados identificavam a existência, em alguns segmentos da população, da idéia de que somente os hoteleiros recebem os benefícios do desenvolvimento.

A falta de visão compartilhada foi outro obstáculo mencionado. Neste caso observou-se que, ao mesmo tempo que se elabora um projeto, não se avaliam detalhadamente as implicações da sua implementação. Ou seja, por se analisar de forma pontual - e não sistêmica - o impacto de uma ação, não se percebem antecipadamente suas conseqüências. Citou-se o exemplo da drenagem do bairro de Capim Macio, que terá um canal que levará as águas pluviais para a Praia de Ponta Negra. Ou seja, para drenar um bairro - algo positivo -,
Quadro 2. Percepção sobre o setor de turismo

\begin{tabular}{|c|c|c|c|c|}
\hline $\begin{array}{l}\text { Organização } \\
\text { pesquisada }\end{array}$ & $\begin{array}{l}\text { Percepção } \\
\text { atual }\end{array}$ & $\begin{array}{l}\text { Pontos } \\
\text { positivos }\end{array}$ & $\begin{array}{l}\text { Pontos } \\
\text { negativos }\end{array}$ & $\begin{array}{c}0 \text { que precisa ser } \\
\text { feito para que } 0 \\
\text { crescimento continue }\end{array}$ \\
\hline $\begin{array}{l}\text { Pirâmide } \\
\text { Palace Hotel }\end{array}$ & Crescimento & $\begin{array}{l}\text { Destino agrada } \\
\text { aos turistas; } \\
\text { investimentos } \\
\text { da iniciativa } \\
\text { privada. }\end{array}$ & $\begin{array}{l}\text { Amadorismo; pouca } \\
\text { divulgação do destino; } \\
\text { falta de agilidade } \\
\text { do governo. }\end{array}$ & $\begin{array}{l}\text { Profissionalização; } \\
\text { regulamentação da } \\
\text { atividade turística; } \\
\text { sensibilização de todos. }\end{array}$ \\
\hline UFRN & Crescimento & $\begin{array}{l}\text { Beleza dos } \\
\text { recursos } \\
\text { naturais } \\
\text { (praia, sol e } \\
\text { clima). }\end{array}$ & $\begin{array}{l}\text { Falta de conscientização } \\
\text { em oferecer o que } \\
\text { o turista deseja; } \\
\text { visão imediatista; } \\
\text { falta de relacionamento } \\
\text { entre as universidades } \\
\text { e o mercado; } \\
\text { marketing restrito à } \\
\text { promoção. }\end{array}$ & $\begin{array}{l}\text { Profissionalização dos } \\
\text { empresários e dos que } \\
\text { trabalham com turismo; } \\
\text { desenvolvimento de } \\
\text { ações mais direcionadas; } \\
\text { produtos compatíveis } \\
\text { com as exigências } \\
\text { do turista. }\end{array}$ \\
\hline $\begin{array}{l}\text { BNB/Pólo Costa } \\
\text { das Dunas }\end{array}$ & Crescimento & $\begin{array}{l}\text { Investimentos } \\
\text { do PRODETUR } \\
\text { I e II. }\end{array}$ & $\begin{array}{l}\text { Prostituição; turismo } \\
\text { sexual, falta de } \\
\text { regulamentação do } \\
\text { uso do solo. }\end{array}$ & $\begin{array}{l}\text { Decisão sobre o tipo } \\
\text { de turista que se quer } \\
\text { para o RN para, a partir } \\
\text { daí, só trabalhar esses } \\
\text { mercados. }\end{array}$ \\
\hline SETUR & Crescimento & $\begin{array}{l}\text { Investimentos } \\
\text { do PRODETUR } \\
\text { I e II. }\end{array}$ & $\begin{array}{l}\text { Especulação imobiliária; } \\
\text { aumento do turismo } \\
\text { sexual; cadastramento } \\
\text { deficiente das empresas. }\end{array}$ & $\begin{array}{l}\text { Regulamentação da } \\
\text { atividade turistica; } \\
\text { planejamento } \\
\text { sustentável; } \\
\text { sensibilização de que } \\
\text { o turismo beneficia a } \\
\text { todos; profissionalização. }\end{array}$ \\
\hline SECTUR & Crescimento & $\begin{array}{l}\text { Retorno } \\
\text { positivo para } \\
\text { os investidores }\end{array}$ & & $\begin{array}{l}\text { Seguimento do Plano } \\
\text { Municipal de Turismo. }\end{array}$ \\
\hline AMHT & $\begin{array}{l}\text { Crescimento } \\
\text { aleatório e } \\
\text { desordenado }\end{array}$ & $\begin{array}{l}\text { Turismo se } \\
\text { tornou uma } \\
\text { atividade } \\
\text { lucrativa. }\end{array}$ & $\begin{array}{l}\text { Ausência do Poder } \\
\text { Público; falta de } \\
\text { participação nas } \\
\text { associações; visão } \\
\text { imediatista. }\end{array}$ & $\begin{array}{l}\text { Projetos de curto, } \\
\text { médio e longo prazos } \\
\text { para o desenvolvimento } \\
\text { do turismo; } \\
\text { profissionalização. }\end{array}$ \\
\hline
\end{tabular}

Fonte: Dados da pesquisa (2004)

Ponta Negra poderá ser prejudicada - algo negativo para o turismo e para o meio ambiente. Questionou-se a capacidade estratégica do Poder Público em face de decisões como essa, tomadas com uma visão tão estreita, sem considerar as implicações na cidade como um todo. 
mais bonita da cidade, em parceria com a rádio Jovem Pan, estimulou a população a enfeitar suas casas e, ao mesmo tempo, mostrou para o Brasil como São Paulo estava se preparando para o Natal. Também foi feita uma campanha publicitária de rádio e TV convidando as pessoas a fazerem compras de Natal em SP e a aproveitar toda a gama de cultura e entretenimento que a cidade oferece.

- Fórmula 1: um videoclipe de 3 minutos com carros de F1 andando por dezenas de pontos turísticos da cidade e a frase "São Paulo: Gateway to Latin America", colocada em um ponto estratégico da transmissão do GP Brasil pela TV, atingiu 390 milhões de espectadores no mundo todo; o Mercado Municipal e muitos restaurantes criaram sanduíches e pratos com o nome de pilotos e escuderias.

Esses, e em especial o da Fórmula 1, são ótimos exemplos de como a cadeia produtiva pode lucrar com os eventos e sua interação com o turismo. Trata-se simplesmente de seguir a teoria do "cluster" de Porter (1998) e aplicá-la com objetividade, ou seja, a teoria se une à prática.

Mas essa relação entre eventos e turismo teve seu ápice no projeto Virada Cultural, que atingiu, de imediato, três dos maiores objetivos da SP TURIS:

1. Envolver a comunidade.

2. Atrair turistas.

3. Mostrar São Paulo como uma cidade de vanguarda, contribuindo para sua imagem de grande metrópole cultural do país e da América do Sul.

Pretende-se fazer isso com muitos outros eventos, entre eles o Réveillon, o Aniversário da Cidade, o Carnaval e a Bienal do Livro, que sempre foram voltados para a população. A partir de 2006, tais eventos não perderão essa característica, mas a usarão para ampliar a auto-estima dos moradores da cidade e, ao mesmo tempo, trazer turistas, assim estarão direcionados ao que é a essência da atividade turística: promover a paz, a confraternização e a melhoria da qualidade de vida da população por meio da distribuição de renda e da ampliação dos empregos e oportunidades.

\section{Ações estratégicas de comunicação}

Todo esse esforço de estruturação do produto precisa ser apoiado por um plano de comunicação consistente. Antes de estabelecer o novo plano, buscou-se identificar os pontos fortes, que atuam como mensagens-chave (key messages) em toda a comunicação da cidade. São eles: cultura, vanguarda, centro de tendên- cias, conhecimento, cidade-mundo. A partir disso desenvolveu-se um novo material de comunicação para o público externo, com folheteria, newsletters semanais e e-mail marketing.

Além disso, tendo-se em vista a resistência do paulistano, já detalhada anteriormente, foi iniciado um trabalho cujo foco é a melhoria da sua auto-estima. Um bom exemplo é o jingle, que foi adotado pela Prefeitura da cidade, chamado "São Paulo, Meu Destino", veiculado em campanhas na TV nos meses de agosto e setembro, e que busca atuar diretamente no "orgulho" do paulistano em ter nascido nessa cidade, ou no do morador, em tê-la escolhido para viver. Essa proposta é claramente perceptível em frases como as seguintes:

- "Me abraça, me beija (...) porque sou a cidade de São Paulo e só quero o seu amor".

- "Mistura de uma raça (...), paulistano-nordestino, a mistura que venceu".

- " "É a alma do Brasil, Europa, Ásia, Oriente, Síria, Japão, Portugal...".

- "Eu sou São Paulo, sou cidade-cidadã, dou pra ti meu coração".

Também está em desenvolvimento um projeto intitulado "São Paulo tem Histórias", que vai expor fatos e personagens da história da cidade, provocando o seu (re)conhecimento, pois muitos, se não a maioria dos paulistanos, moradores e visitantes os desconhecem. Esse trabalho é complementado pelo site www.saopaulominhacidade.com.br, no qual a população conta histórias sobre a cidade, do passado e do presente. O objetivo é, além de resgatar a memória de São Paulo, aumentar a auto-estima do paulistano, humanizando a metrópole por meio de suas histórias cotidianas, cheiros, sons, romances etc.

Começam a ser desenvolvidas campanhas que aproveitam o momento, como a que estimula as compras de Natal em São Paulo. E outras virão para entrar nessa mudança de percepção, inclusive uma que estimula os viajantes de negócios a ficarem mais um dia na cidade. É a campanha "Fique mais um dia". Também nessa linha trabalha-se com os turistas internacionais para ficarem mais um dia $\mathrm{e}$ vivenciar uma metrópole rica culturalmente, que possui toda uma gama diversificada de entretenimentos para todo e qualquer segmentos de público, para toda e qualquer motivação, necessidade ou expectativa.

\section{Considerações finais}

O grande desafio atual é transformar São Paulo em uma cidade global, fazendo-a crescer como uma metrópole organizada, que realiza arranjos produtivos para melhorar a qualidade de vida de sua população. Não é motivo de orgulho 
Isso permitiu avaliar que a falta de articulação, integração e visão, além da carência de informações entre os vários níveis de decisão, dificulta o desenvolvimento do setor, apesar da existência daqueles fóruns. O Quadro 3 mostra a sintetização das respostas dadas pelos entrevistados.

Com relação à visão existente a respeito do turismo e de suas organizações, verificou-se que há uma diferença na amplitude da análise, bem como nas ações presentes que visam ao enfrentamento dos desafios do futuro. Percebeu-se que as organizações se restringem a analisar o ambiente atual e seus obstáculos, não havendo objetividade nas explicações de como se planeja, a partir de ações realizadas nopresente, construir um amanhã. Observou-se, conforme pode ser verificado

\section{Quadro 3. Visão compartilhada entre as organizações que compõem o turismo}

\begin{tabular}{|c|c|c|c|}
\hline $\begin{array}{l}\text { Organização } \\
\text { pesquisada }\end{array}$ & $\begin{array}{c}\text { Visão } \\
\text { compartilhada }\end{array}$ & Causas & Solução \\
\hline $\begin{array}{l}\text { Pirâmide } \\
\text { Palace Hotel }\end{array}$ & Parcialmente & $\begin{array}{l}\text { Percepção de que o turismo } \\
\text { só traz benefícios para } \\
\text { os hoteleiros. }\end{array}$ & $\begin{array}{l}\text { Conscientização e } \\
\text { campanha de sensibilização } \\
\text { promovida pelo SECTUR. }\end{array}$ \\
\hline UFRN & Parcialmente & $\begin{array}{l}\text { Atitude dos dirigentes que } \\
\text { acham que sabem de tudo; } \\
\text { existência de competição } \\
\text { destrutiva. }\end{array}$ & $\begin{array}{l}\text { Profissionalização; } \\
\text { participação nos fóruns } \\
\text { existentes, como o } \\
\text { CONETUR e o Pólo Costa } \\
\text { das Dunas; cooperação. }\end{array}$ \\
\hline $\begin{array}{l}\text { BNB/Pólo Costa } \\
\text { das Dunas }\end{array}$ & Parcialmente & $\begin{array}{l}\text { Interesse particular fala } \\
\text { mais forte; falta de } \\
\text { informação. }\end{array}$ & Conscientização. \\
\hline SETUR & Parcialmente & $\begin{array}{l}\text { Falta de regulamentação } \\
\text { da atividade turística. }\end{array}$ & $\begin{array}{l}\text { Participação nos fóruns } \\
\text { existentes, como o } \\
\text { CONETUR e o Pólo Costa } \\
\text { das Dunas; visão de longo } \\
\text { prazo e definição do que } \\
\text { se deseja para o futuro } \\
\text { do RN. }\end{array}$ \\
\hline SECTUR & Parcialmente & $\begin{array}{l}\text { As empresas ainda não } \\
\text { despertaram para a } \\
\text { necessidade da ação } \\
\text { conjunta para que o } \\
\text { turismo se desenvolva. }\end{array}$ & $\begin{array}{l}\text { Participação dos fóruns } \\
\text { existentes, como o } \\
\text { CONETUR e o Pólo Costa } \\
\text { das Dunas. }\end{array}$ \\
\hline AMTH & Não & $\begin{array}{l}\text { Visão limitada aos } \\
\text { próprios problemas. }\end{array}$ & $\begin{array}{l}\text { Participação ativa nas } \\
\text { associações. }\end{array}$ \\
\hline
\end{tabular}

Fonte: Dados da pesquisa (2004) no Quadro 4, que a ligação entre as ações de hoje e o ambiente futuro é tênue. Porém, foi identificado que existem profissionais qualificados no meio acadêmico, inclusive com formação na área de cenários, que poderiam estar à frente de um projeto como esse.

Com relação à instituição de ensino superior, considera-se tímida a participação da universidade no desenvolvimento do setor de turismo por conta dos seguintes motivos:

1) falta de incentivo para que os professores que estudam e pesquisam temas de turismo atuem de maneira pró-ativa;

2) falta de objetividade dos trabalhos desenvolvidos pelas áreas de pesquisa e ensino por não haver uma preocupação com as reais necessidades do setor;

3) existência de pouco contato entre os professores e o mercado;

4) presença, no empresário, do receio de que informações estratégicas de seu negócio sejam transmitidas à concorrência por meio dos trabalhos apresentados no meio acadêmico. Isso explica por que essas pessoas se tornam resistentes em disponibilizar dados de suas empresa para pesquisa;

5) inexistência de um reconhecimento do potencial existente nas universidades, nas áreas de pesquisa e ensino, pelos empresários do setor.

Houve concordância, entre os entrevistados, de que existe interdependência entre as organizações do setor de turismo, porém essa interdependência só começou a ser percebida após a implantação do Pólo Costa das Dunas. A forma como cada um reagiu a esse fato variou, mas na iniciativa privada, as empresas ainda tentam ser independentes, buscando apoio apenas quando necessário. Tal atitude é recente e surgiu com o nascimento do Pólo Turístico da Via Costeira, ao qual estão associados os nove hotéis situados na Via Costeira. A consciência da interdependência deveu-se à constatação de que não era mais possível esperar pela ação do governo para resolver os problemas comuns, sendo o governo visto como possuidor de reações lentas, o que ocasionava a perda de muitas oportunidades.

Com base no exposto, observa-se que, como a atenção das entidades e organizações está voltada para o presente, ou para o curto prazo, o planejamento não é feito visando à antecipação de como os stakeholders envolvidos poderiam agir, de forma a aproveitar as oportunidades, o que leva à perda do timming para fazer as coisas. Em estratégia acredita-se que a visão de longo prazo, a definição do futuro desejado, mais a observação do que pode acontecer, e como, são elementos que possibilitam às organizações tornarem-se mais competitivas. 
Quadro 4. Visão estratégica do setor de turismo e de suas organizações

\begin{tabular}{|c|c|c|}
\hline $\begin{array}{l}\text { Visão } \\
\text { estratégica }\end{array}$ & $\begin{array}{l}\text { Organizações } \\
\text { Pesquisadas }\end{array}$ & Açōes \\
\hline $\begin{array}{l}\text { Aumento da concorrência para os } \\
\text { hotéis cinco estrelas locais, } \\
\text { por causa da vinda de redes } \\
\text { internacionais; aumento da } \\
\text { exigência dos turistas estrangeiros; } \\
\text { possibilidades de se fazerem } \\
\text { alianças estratégicas ou de vendas } \\
\text { do empreendimento. }\end{array}$ & $\begin{array}{l}\text { Pirâmide Palace } \\
\text { Hotel }\end{array}$ & $\begin{array}{l}\text { 1) obtenção da classificação de } \\
\text { cinco estrelas; } \\
\text { 2) intensificação da participação em } \\
\text { feiras internacionais; } \\
\text { 3) captação de novos vôos charter; } \\
\text { 4) investimentos no hotel, como a } \\
\text { criação de um spa, visando ao } \\
\text { público estrangeiro; ampliação } \\
\text { do bar da piscina; } \\
\text { 5) estruturação da parte comercial } \\
\text { em Recife e São Paulo. }\end{array}$ \\
\hline $\begin{array}{l}\text { A UFRN deve ter um papel mais } \\
\text { significativo no trade turístico. }\end{array}$ & UFRN & $\begin{array}{l}\text { Implantação do Pólo Costa } \\
\text { das Dunas. }\end{array}$ \\
\hline $\begin{array}{l}\text { Visualização de que o turismo } \\
\text { crescerá em todo o Estado, e de } \\
\text { que a sociedade, aos poucos, } \\
\text { será sensibilizada a respeito dos } \\
\text { benefícios que a atividade traz } \\
\text { para a cidade. }\end{array}$ & $\begin{array}{l}\text { Banco do Nordeste / } \\
\text { Pólo Costa das Dunas }\end{array}$ & $\begin{array}{l}\text { 1) PRODETUR I e II; } \\
\text { 2) implantação do Pólo Costa } \\
\text { das Dunas. }\end{array}$ \\
\hline $\begin{array}{l}\text { Natal está consolidado como pólo } \\
\text { turístico; no entanto, é preciso que } \\
\text { se façam intervenções, de modo } \\
\text { a organizar esse crescimento. }\end{array}$ & SETUR & $\begin{array}{l}\text { 1) PRODETUR I e II; } \\
\text { 2) ação do Pólo Costa das Dunas e } \\
\text { do CONETUR. }\end{array}$ \\
\hline $\begin{array}{l}\text { Visualização de que o turismo } \\
\text { crescerá apesar de, na empresa } \\
\text { pública, pela descontinuidade que } \\
\text { existe entre as gestões, ser difíiil } \\
\text { ter esse tipo de visão. }\end{array}$ & SECTUR & $\begin{array}{l}\text { 1) desenvolvimento do Plano } \\
\text { Municipal do Turismo; } \\
\text { 2) campanhas para a } \\
\text { conscientização da população } \\
\text { sobre a importância do turismo; } \\
\text { 3) ações visando à preservação do } \\
\text { meio ambiente. }\end{array}$ \\
\hline $\begin{array}{l}\text { Apesar de a associação ter um } \\
\text { papel decisivo na busca de soluções } \\
\text { para a categoria, sua ação é } \\
\text { dificultada pela pouca participação } \\
\text { dos associados, que só a procuram } \\
\text { quando estão com algum } \\
\text { problema específico. }\end{array}$ & AMHT & $\begin{array}{l}\text { 1) obtenção de representatividade } \\
\text { política por meio da candidatura } \\
\text { de uma pessoa ligada ao } \\
\text { segmento turístico; } \\
\text { 2) criação de mecanismos para } \\
\text { diminuir a dependência da } \\
\text { ação do governo. }\end{array}$ \\
\hline
\end{tabular}

Fonte: Dados da pesquisa (2004).
As secretarias de governo estadual e municipal atuam, na maioria das vezes, em parceria com outros órgãos para realizar suas ações. Seus principais parceiros são o governo federal, o Banco do Nordeste, o SEBRAE, as associações de classe, as universidades e os fóruns constituídos, como o Pólo Costa das Dunas, o conetur e o Conselho Municipal de Turismo. Percebeu-se, diante disto, que existem vários stakeholders com interesses relacionados à atividade turística e que sua ação, ou a falta dela, pode interferir no desenvolvimento do setor. Se houvesse um entendimento comum, compartilhado por todos, notadamente no que diz respeito à percepção de como o que acontece nos vários níveis do macroambiente pode afetar o presente e seu futuro, provavelmente haveria maior interesse em avaliar todas as influências externas e seus impactos no turismo. A teoria mostra que o uso de cenários possibilitaria que escolhas estratégicas fossem feitas de forma coerente $\mathrm{e}$ consistente com o futuro desejado para o turismo. Cenários, se usados adequadamente, poderiam propiciar um ambiente setorial no qual todos se conscientizassem de que fazem parte do mesmo produto turístico, e de que a ação individual e conjunta, de forma integrada, é necessária. A participação de todos os atores no planejamento das estratégias setoriais é fundamental para que eles se comprometam com o processo. Eis aí um dos principais benefícios da metodologia em questão.

\section{Conclusões}

A aplicação dos estudos sobre a temática do futuro no contexto das organizações é desafiadora na medida em que, na realidade, vê-se uma preocupação quase exclusiva com questões essencialmente ligadas ao momento presente. Trata-se de uma abordagem relativamente nova e ainda em processo de assimilação pela maioria das organizações, que buscam sustentabilidade a longo prazo num mercado cada vez mais competitivo.

O presente estudo insere-se nesse contexto, procurando discutir a visão de futuro, sua natureza, significado e implicações por meio dos diversos autores e seus enfoques, além de realizar investigação de campo para conhecer até que ponto e como as empresas e instituições ligadas ao setor do turismo desenvolvem suas visões de futuro.

Em termos conclusivos, o estudo verificou que as instituições do setor do turismo pesquisadas não desenvolvem visão de futuro compartilhada entre os seus dirigentes, o que se deve, em muito, à falta de sintonia quanto à própria atividade, sua importância e seus benefícios, e às diferenças na perspectiva de análise sobre o que está sendo feito atualmente para enfrentar os desafios do futuro. Essas instituições limitam seu escopo de análise e ação ao ambiente presente, en- 
volvidas que estão com suas problemáticas e seus obstáculos, não havendo determinação e objetividade sobre como planejar a construção do amanhã.

Apesar de haver um sistema de fóruns congregando todos os representantes das esferas pública e privada, bem como a comunidade, onde são discutidos e apresentados encaminhamentos e soluções para o setor, isso não é aproveitado nem incorporado à dinâmica dos planos e projetos das organizações, o que poderia favorecer a visão compartilhada. Há discordância em vários aspectos sobre a participação, envolvimento e papéis das empresas nesse ambiente, e ainda sobre a necessidade de definição do que se deseja para o turismo, sobre o que é preciso fazer e como deve ser feito.

Pode-se, por fim, saber que não há consenso suficientemente desenvolvido para conceber, pensar e implementar uma visão de futuro que congregue as contribuiçōes individuais e específicas em torno de uma perspectiva mais ampla, que englobe as múltiplas dimensōes da complexa atividade turística, fortalecendo as instituiçōes e o setor como um todo tanto no espaço como no tempo, visando a um futuro alinhado às grandes estratégias e sustentado competitivamente.

Vale ressaltar, por fim, que os resultados alcançados devem ser considerados mais especificamente para o contexto das empresas estudadas, embora tais resultados apontem pontos relevantes, que podem contribuir para o estudo da visão estratégica. Também se pode afirmar que, dentro das limitaçōes científicas, as generalizações ficam prejudicadas. Isso pode sugerir a indicação de outros estudos sobre o assunto para ampliar uma necessária compreensão do complexo e delicado fenômeno do futuro para as organizaçōes e para os setores das diversas atividades econômico-sociais ligadas ao turismo.

\section{Referências bibliográficas}

ACHE, P. 2000. Vision and creativity: challenge for city regions. Futures, v. 32 , no ${ }^{0}$, jun., p. $435-449$

AHMED, A. M. \& ABDALLA, H. S. 1999. The role of innovation process in crafting the vision of the future. Computers es Industrial Engineering, v. 37, issues 1-2, oct., p. 421-424.

AIDEMARK, L. G.\& LINDKVIST, L. 2004. The vision gives wings: a study of two hospitals run as limited companies. Management Accounting Research, v. 15, no 3, Sep., p. 305-318.

ASHLEY, C. W. \& HALL, L. 1985. In: MENDELL, J. S. Nonextrapolative methods in business forcasting: scenarios, vision and issues management. Westport: Quorum Books.

ATHANASSIOU, N. et al. 2002. Founder centrality effects on the Mexican family firm's top management group: firm culture, strategic vision and goals, and firm performance Journal of World Business, v. 37, iss. 2, p. 139-150.
BERTODO, R. 1990. Implementing a strategic vision. Long Range Planning, v. 23, n² 5, oct., p. 22-30. 1991. The role of suppliers in implementing a strategic vision. Long Range Planning, v. $24, \mathrm{n}^{2} 3$, jun., p. $40-48$

BRABET, J. \& KLEMM, M. 1994. Sharing the vision: Company mission statements in Britain and France. Long Range Planning, v. 27, nº 1, feb., p. 84-94.

CAVANAGH, R. \& SONSTELIE, R. 1998. Energy distribution monopolies: a vision for the next century. The Electricity Journal, v. 11, no 7, 9, aug., p. 13-23.

COSTA, E.A. 2002. Gestão estratégica. São Paulo: Saraiva.

COULSON-THOMAS, C. 1992. Strategic vision or strategic rhetoric or reality? Long Range Planning, v. 25, noo 1, feb., p. 81-89.

CURRIE, W. L. 1999. Revisiting management innovation and change programmes: strategic vision or tunnel vision? Omega, v. 27, nº 6, dec., p. 647-660.

2004. The organizing vision of application serviceprovision: a process-oriented analysis. Information and Organization, v. 14, no 4, oct., p. 237-267.

DE GEUS, A. P. 1988. Planning as learning. Harvard Business Review, marc/apr., p.70-74

EL-NAMAKI, M. S. S. 1992. Creating a corporate vision. Long Range Planning, v. 25, no 6, dec., p. 25-29.

FRASER, V. J. \& OLSEN, M. A. 2002. The business of health care epidemiology: creating a vision for service excellence. American Journal of Infection Control, v. 30, nํㅡ 2, apr., p. 77-85.

GODET, M. 2001. Creating futures: scenario planning as a strategic management tool. Paris: Economica.

GRATTON, L. 1996. Implementing a strategic vision - key factors for success. Long Range Planning, v. 29, no 3, jun., p. 290-303.

HAECKEL, S. H. 2004. Peripheral vision: sensing and acting on weak signals: making meaning out of apparent noise: the need for a new managerial framework. Long Range Planning, v. 37, Iss. 2, apr., p. 181-189.

HAMEL, G. \& PRAHALAD, C.K. 1995. Competindo pelo futuro. 10. ed. Rio de Janeiro: Campus.

HART, Ellen R. 1999. Mudança estratégica: reconfigurando os processos operacionais para a implementação de estratégia. In: FAHEY, Liam \& RANDALL, Robert M. MBA curso prático de estratégia. 2. ed. Rio de Janeiro: Campus.

HASSAN, T.M. \& McCAFFER, R. 2002. Vision of the large scale engineering construction industry in Europe. Automation in Construction, v.v1l, no 4, jun., p. 421-437.

HAX, A. C. \& MAJLUF, N. S. 1996. The strategy concept and process. 2. ed. Englewood Cliffs, NJ: Prentice-Hall.

HOFER, Charles W. \& SCHENDEL, Dan. 1978. Strategy formulation: analytical concepts. St Paul - Minnesota: West Publishing.

JOHNE, A. 1999. Using market vision to steer innovation. Technovation. v. 19, nº 4, feb., p. 203-207. JOHNSON, G. \& SCHOLES, K. 1999. Exploring corporate strategy: text and cases. 5. ed. New York: Prentice-Hall. 
LISSACK, M. \& ROOS, J. 2001. Be coherent, not visionary. Long Range Planning, v. 34, nº 1, feb., p. 53-70.

MAJOR, E.; ASCH, D. \& CORDEY-HAYES, M. 2001. Foresight as a core competence. Futures. v. 33, p. 91-107.

MARKLEY, O.W. 1994. Rethinking the legacy of Columbus: a vision of business - university collaboration between North and South. Futures. v. 26, nº 7, sept., p. 771-780.

MOULE, P. 1999. Contracting for nurse education: nurseleader experiences and future visions. Nurse Education Today, v. 19, n 2, feb., p. 164-171.

NAKAHARA, T. \& ISONO, Y. 1992. Strategic planning for Canon; The crisis and the new vision. Long Range Planning, v. 25, nº 1, feb., p. 63-72.

PEPPARD, J. 1996. Broadening visions of business process re-engineering. Omega, v. 24, n 3, jun., p. 255-270.

RITCHIE, J. R. B. 1999. Crafting a value-driven vision for a national tourism treasure. Tourism Management. v. 20, nº 3, jun., p. 273-282.

SCHOEMAKER. P. J. H. 2002. Profiting from uncertainty: strategies for succeeding no matter what the future brings. New York: Free Press.

SENGE, P. M. 1998. A quinta disciplina. São Paulo: Best Seller.

SELLTIZ, C. et al. 1965. Métodos de pesquisa nas relações sociais. São Paulo: EPu.

SHIRLEY, Steve. 1989. Corporate strategy and entrepreneurial vision. Long Range Planning, v. $22, \mathrm{n}^{\circ}$ 6, dec., p. 107-110.

THORNBERRY, N. 1997. A view about 'vision'. European Management Journal, v. 15, nº 1, feb., p. 28-34.

WILSON, I. 1992. Realizing the power of strategic vision. Long Range Planning, v. 25, nº 5, oct., p. 18-28.

WITTLÖV, A. 2001. The long term vision for aeronautics. Air \& Space Europe, v.3, nº 3-4, mayaug., p. 42-44.

XU, X. M.; KAYE, G. R. \& DUAN, Y. 2003. UK executives' vision on business environment for information scanning: a cross industry study. Information \& Management, v. 40, $\mathrm{n}^{\circ}$ 5, may, p. 381-389.

YIN, R. K. 1994. Case study research: design and methods. 2. ed. Thousand Oaks: Sage Publications.

Recebido em: 13/04/2005.

Aprovado em: 25/06/2005. 